\title{
New Artificial Muscle Filament Mechanism Based on Fluids Chemical Reaction and Natural Principle
}

Ramin Zakeri ${ }^{1,2^{*}}$ and Reza Zakeri ${ }^{2}$

${ }^{1}$ Faculty of Mechanical Engineering, Shahrood University of Technology, Shahrood, Iran

${ }^{2}$ Shahrood Science \& Technology Park, Shahrood, Iran

\begin{abstract}
In this research, an artificial muscle filament (AMF) as a novel mechanism and small part of the artificial muscle is proposed in which, considering the real natural mechanism and necessity and constructability of industrial manufacturing engineering, AMF with no electric power supply for expansion/contraction provides the conspicuous strong and fast displacement. AMF, inspired by nature, based on the sliding filament theory and combination of advantages of soft and hard materials, employs artificial actin (AA, scissor mechanism) and artificial myosin (AM, soft material). Volume change of AM for displacement of $A A$ is resulted from proposed chemical reaction of sodium bicarbonate $(\mathrm{NaHCO} 3(\mathrm{~s})$ ) solution with water (I) and acetic acid ( $\mathrm{CH} 3 \mathrm{COOH}(\mathrm{I})$ ) which the main advantages of high power to weight ratio (more than 10 times), mimicking nature and expandable to artificial muscle are obtained in simple module structure. Response speed of AMF can be adjusted by controlling the flow rate and gas output from less than 1 second to desired amount. In this study, by applicable notice on numerical simulation of particle dynamics and experimental tests of AM, a laboratory model of AMF with displacement of 50 $\mathrm{mm}$ has been fabricated which for various ranges of flow rate and loading condition is evaluated. The AMF based on the filament theory close to nature, due to overcoming the limitation of conventional artificial muscle and correspondingly advantages of simplicity in fabrication and modularity, low cost and weight, high power and fast response time, the proposed mechanism may be employed especial place for the some future industrial applications.
\end{abstract}

\section{Keywords}

Artificial muscle filament, Myosin, Actin, Fluids chemical reaction, Particle dynamics simulation, Experimental tests

\section{Introduction}

Movement of humans and animals depend on displacement of muscles which are related to contraction/relaxation of fibers and finer components [1-3]. Despite to intricate mechanism of muscle, it can easily provide light weight, flexible and high power operation in complex environments without need any electrical power which by observation of limitations in conventional soft and rigid mechanisms, returning to the nature and corrections of engineering systems and sub-systems are essential $[4,5]$.

*Corresponding author: Ramin Zakeri, Faculty of Mechanical Engineering, Shahrood University of Technology, Shahrood, Iran

Accepted: December 29, 2020; Published: December 31, 2020

Copyright: (c) 2020 Zakeri R, et al. This is an open-access article distributed under the terms of the Creative Commons Attribution License, which permits unrestricted use, distribution, and reproduction in any medium, provided the original author and source are credited.

Zakeri R, et al. Int J Robot Eng 2020, 5:030

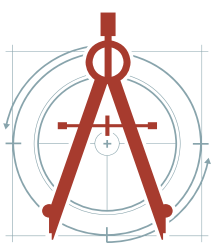


From industrial aspect, movement of mechanical mechanisms play important role in the numerous applications such as robotic technology for example motion of arm robot [6], a variety of applications in medical world such as equipment to assist human muscular strength [6,7], aerospace for manufacturing active surface control of morphing airfoil [8], Unmanned underwater vehicles [9] and other applications which displacement based on the natural principle as a perfect resource for inspiring may be followed by some industrial sectors in the soon future.

There are several recent methods to provide movement in which each of them has own pros and cons. In general, movement of robot can be categorized into two groups including hard and soft robots. Most of the rigid robots use servo or electrical motors or hydraulic packs which need of electrical power and having high weight compared to power are related to these methods $[10,11]$. Bai, et al. [12] used the servo drive and developed joint servo with adaptive back-stepping control on humanoid robot. Despite high control on servo motor, working on complex environment for electric motor is a noticeable problem. One of the long standing challenges and working in the complex environments is adaptive and resilient mechanisms to provide flexible movements $[9,13]$. For this reasons, huge researches in relation to soft robot and displacement have been performed. Various types of soft robots employ several methods for motion to overcome mentioned restrictions. Yeom, et al. [14] applied ionic polymer metal composite actuator with pulse and recovery processes to mimic real behavior of jellyfish robot. Also, Yang, et al. [9] presented a soft robot equipped with dielectric elastomer artificial muscle to mimic cuttlefish movement [9]. Guo, et al. [15] employed the ionic conducting polymer for providing the soft movement of biomimetic fish-like microrobot. The mentioned methods depend on electric power [16] and extra high voltage and will have low output power. There are several methods which are independent of high voltage and electric power. Shape memory alloy is an especial alloy that can change heat energy to mechanical movement. Han [17] used this method to show blooming the knit flowers. Lancia [18] studied on artificial molecular machines motion which has been amplified into the shape transformation of polymer materials or polyvinyl chloride gel also response to gradient temperature $[12,19]$. Although these methods can be used independent from electric power, but large displacement in short period of time especially in various loading conditions, which this methods lack of it, is a requirement for an applicable artificial muscle. Also, there are several hydrogel materials with conspicuous properties and variety nano structure which can be applicable in the field of artificial muscle. Ganguly, et al. [20] used the poly (methacrylic acid) grafted polysaccharide based semi-IPNs filled with nanoclay to study the effect of nanoclay in the semi-IPN hydrogel. They showed that applied features in a single hydrogel assembly will be applicable in biomaterial for tissue engineering. Amiri, et al. [21] applied the composition and synthesis of hydrogel beads to develop this material as a biocompatibility and biodegradability for novel drug delivery platforms. It should be noted that, despite remarkable characterization of hydrogel for artificial muscle applications, a real natural muscles shows a conspicuous displacement with applicable power with distinct mechanism which more investigations in this field are necessary [2027].

Recently, artificial muscle based on the vacuum is an interesting method, especially large displacement in quick response time even in high loading condition has been proofed as significant advantages of this method, however, need to strong compressor and lack of proper mechanism close to natural models, as the perfect and flawless systems, are observed for this approach [20,21,28-31]. Due to these limitations, returning to nature and mimicking the similar natural mechanisms have been noticed in this paper. According to all similar muscle mechanisms in nature, the key of displacement becomes brief in movement of myosin and actin through a myofilament as small part of myofibrils [31]. Krans [32] described the muscle contraction based on the sliding movement between myosin and actin [31]. Mitsui, et al. [33] used the thermodynamics model to explain muscle contraction mechanism based on the sliding-filament theory. Finding a proper industrial mechanism based on the nature need to be understood the mechanism and be replaced each natural element of filament with an artificial components considering the feasibility of industrial manufacturing.

Although, relying on current methods and other researches, inflation/deflation of soft material shows interesting results but most of the research- 
es need to be improved based on the real nature [34-37]. By taking close look at the nature and sliding filament theory, small amount of fluid in high pressure has enough potential to displace actin in sliding movement and using huge amount of fluid in big bag for creation of displacement is far from nature [37]. Trapping small amount of fluid in small soft material, can easily inflate it and transfer force because of lower friction compared to reciprocating piston type syringe. From another side, in contraction of filament, several action of myosin is necessary. Scissor mechanism can boost small amount of linear displacement to higher sliding motion. For this purpose, considering the restriction of some researches depend on high voltage and electric power $[9,14,15]$, lack of large displacement and quick response time $[12,18,19]$ in high loading condition and some mechanisms far from nature $[29,34]$, in this paper, by employing the chemical reaction with proper control mechanism and the combination of scissor mechanism (hard material) and inflation of soft material, mimicking the nature, the AMF are presented as a novelty of this study.

Operation principle of natural muscle and proposed AMF are compared in Figure 1. By emphasizing on sliding filament theory, Figure $1 \mathrm{~A}$, the most accepted theory for mechanism of muscle contrac-

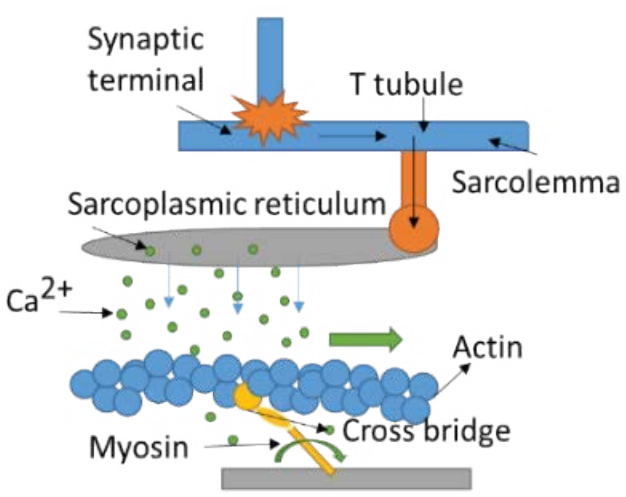

(a)

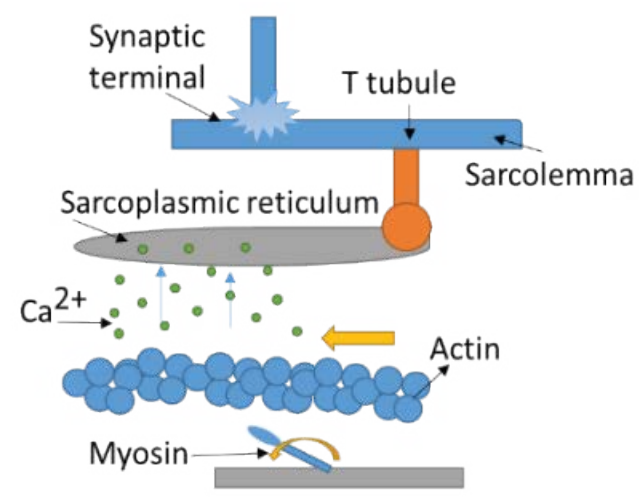

(b)

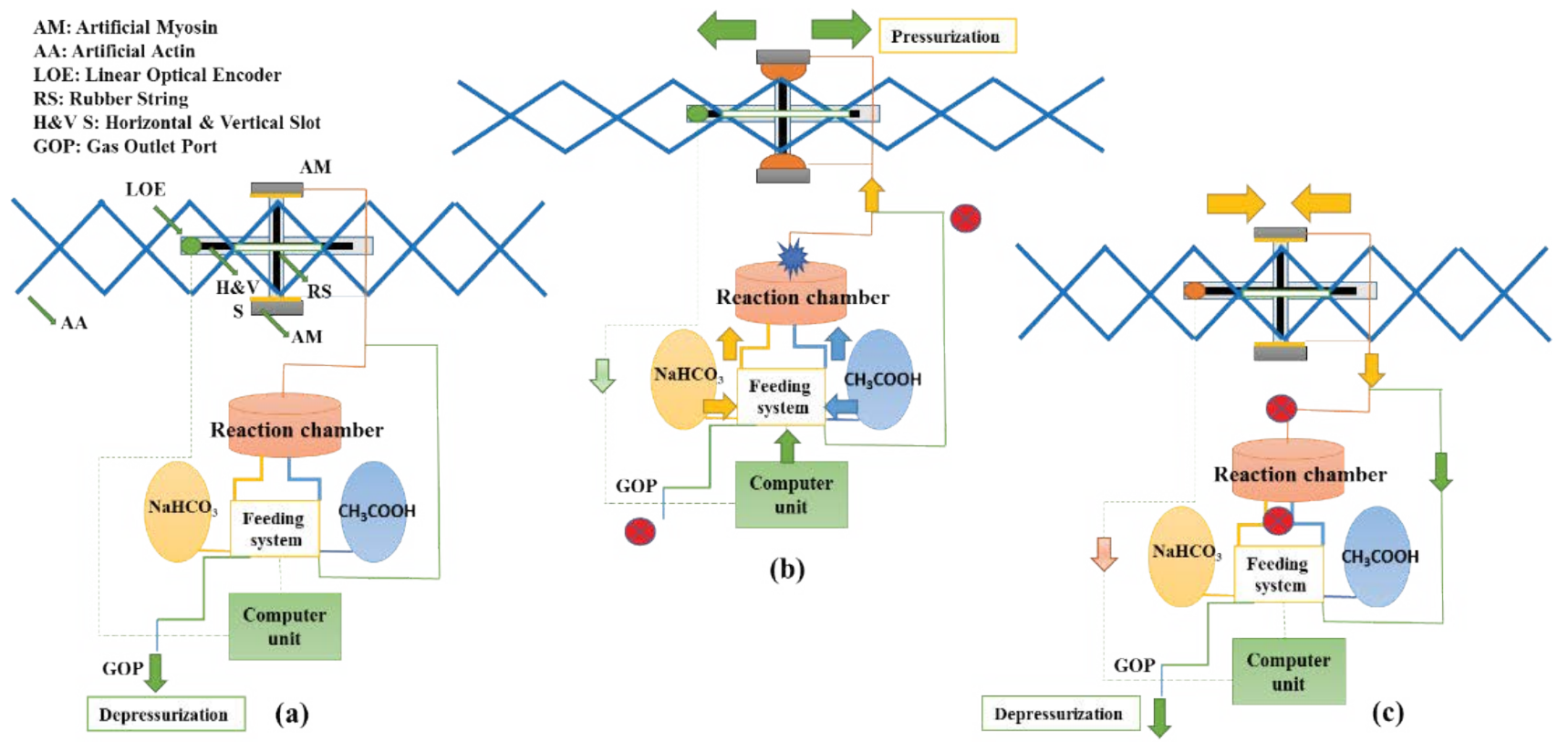

Figure 1: Principle of operation of natural MF and proposed AMF. (A-a) Action of myosin because of changing the ATP to ADP by releasing the calcium, stimulated by synapse, from sarcoplasmic reticulum and formation of cross bridge and contraction of actin is resulted. (A-b) Relaxation of actin, filament and consequently muscle fiber caused by returning of calcium to sarcoplasmic reticulum and inactivation of myosin; (B-a) Components of proposal AFM; (B-b) inflation of AM and movement of AA (scissor mechanism) due to reaction of $\mathrm{NaHCO}_{3}$ (s) and $\mathrm{CH}_{3} \mathrm{COOH}$ and pressurization process by closing the GOP; (B-c) Releasing the gas from GOP, inactivation of $A M$ and relaxation of $A A$ due to LOE comment in depressurization process. 
tion [1], in the first step, a motor neuron carries signal from the central nervous system (CNS) to the muscle fiber, which generates an action potential. In the second step, the action potential causes the release of calcium ions from the sarcoplasmic reticulum. Calcium ions bind to troponin on actin, thus exposing the binding sites for myosin. In the third step, Movement of myosin is resulted from changing of $A T P^{1}$ to $A D P^{2}$ and transfer of energy occurs. The myosin heads bind to the actin, forming a cross-bridge that pulls the actin filaments causing them to slide over the myosin filaments, thus casing contraction. In the fourth step, calcium back to the sarcoplasmic reticulum and actin become inactive; Cross bridges are broken and the muscles relax $[1,2]$.

Also, In this research, the forth main steps are considered and artificial components are employed for forming a complete displacement (Figure 1B) which soft material (natural rubber) and hard material are applied as an artificial myosin and scissor mechanism respectively, also, computer unit (artificial CNS) is used to deliver feeding and control the active or inactive progress. Computer unit sends signal to feeding system to release the solution of water with sodium bicarbonate and acetic acid and then combine them in reaction chamber [38] to produce enough potential for displacement (action potential). Then, based on the equation of $\mathrm{NaHCO}_{3}(\mathrm{~s})+\mathrm{CH}_{3} \mathrm{COOH}(\mathrm{I}) \rightarrow \mathrm{CO}_{2}(\mathrm{~g})+\mathrm{H}_{2} \mathrm{O}(\mathrm{I})+\mathrm{Na}^{+}$ (aq) $+\mathrm{CH}_{3} \mathrm{COO}^{-}(\mathrm{aq})$, the produced gas is used for actuation of soft material (natural rubber) or artificial myosin (second step). In the third level, cross bridge between $A M$ and $A A$ should be formed (cross bridge). It is noticeable that in the real mechanism of nature, several action of myosin create a large displacement, in this research, by utilizing the scissor mechanism, small displacement to higher shift can be reinforced in just one action of AM and noticeable displacement is formed. By checking the amount of displacement using linear optical encoder, the signal sends to computer as feedback line, in the last traveling counter, depressurization of reaction chamber is carried out by gas outlet port (depressurization) and, because of rubber string, the AM will be returned to initial position to complete the forth step or relaxation of AMF.

\section{${ }^{1}$ Adenosine tri-phosphate.}

${ }^{2}$ Adenosine diphosphate.
In this paper, based on the forth main steps, it should be realized that small amount of gas in high pressure would be enough to inflate the $A M$ and moves AA in sliding motion. Combination of soft material for AM (decreasing the friction compared to direct contact methods), hard material in $A A$ (complete and multiply transfer) with contribution and accessibly to high pressure (proper chemical reaction) and smart control system lead to large sliding displacement in regard to natural principle.

\section{Materials and Methods}

The method for numerical section is Dissipative Particle Dynamics (DPD) simulation method as a famous method for soft material simulation, which aims to simulate a soft material against pressure changes. In the description section, it will be explained in more detail (see section 5.2) [39].

In the experimental section, combination of soft and hard material has been used to make artificial myosin and actin. The soft material is made of natural rubber and the hard material is aluminum in the form of a thin strip. Also, the $\mathrm{NaHCO}_{3}(\mathrm{~s})$ and $\mathrm{CH}_{3} \mathrm{COOH}$ (I) as desired chemical materials have been selected to increase the pressure of the soft materials. To control the reaction, hardware setup and subsystems, electronic circuits and coding (program the chips) have been used in this regards (section 5.3). Details of the method and materials are given as follows (also see section 5.3, 5.3, 5.4, 5.5):

Chemical materials: Using the natural rubber for applying the soft material in $\mathrm{AM}$ and rubber string, sodium bicarbonate $\left(\mathrm{NaHCO}_{3}(\mathrm{~s})\right)$ and acetic acid $\left(\mathrm{CH}_{3} \mathrm{COOH}(\mathrm{I})\right)$ as a reactive fluids.

Mechanical materials: Thin rectangular aluminum bar (10 $\mathrm{mm}$ width) for making the scissor mechanism or AA, Acrylic sheet and laser cutting to make main structure of AMF, Syringe $(5 \mathrm{~mL})$ as a reservoir and making the reaction chamber, rubber lines and connector and splitter for transferring the fluids, fasten the lines to components or splitting the fluids respectively and sliding mechanism for making the AM tester.

Electric and electronic materials: Using AVR-Microchip (8-mega) as a main processor of inputs/outputs, module L298 for deriving the DC-motor or micro pump (manipulated printer pump), module TTL to USB for changing PC data to com-port, module PIR sensitive to heat of body instead of PC for re- 
peating the tests, optical encoder $\mathrm{MH}$ for detection of displacement, Micro Servo (Tower Pro) as a controllable gas valve and power supply of 12 and 5 volt.

Programing: FORTRAN code of dissipative particle dynamics for numerical simulation, BASCOM-AVR programing for running the electronic equipment.

\section{Results and Discussion}

In this section, the numerical and experimental results of the proposed idea are examined. In the numerical section, a polymer membrane is simulated which, due to soft and flexible properties, it will perform like a real soft and flexible membrane and displacement is resulted [39]. In the experimental section, the displacement of a soft material is investigated and then by employing the scissors mechanism and combining it with the soft material, a significant displacement is obtained.

\section{DPD-Numerical simulation of AM}

As it is obvious, motion mechanism of natural myosin has been changed to inflation/deflation of soft material in an AMF, which further investigation in this component should be taken into account. Some scholars have noticed that using soft material and power of fluid can pressurize bag or be evacuated for deflation, called origami-inspired artificial muscles [28], these mechanism are reported that can lift objects more than 1000 times more than own weights. To specify behavior of this component, simulation of inflation of AMF is carried out for the first time using dissipative particle dynamics (DPD) [39-43]. DPD is a particle based method for simulation of fluids especially in the case of interaction of fluid particles and membrane particles or polymer chain, this approach has been recently applied for this type of simulation. For simulation of inflation of soft material due to pressure of fluid, the membrane or soft material can be assumed that combination of mass (bead) and spring (harmony bond constant) provide a thin layer which prevent particles from going out. There are several interactions between particles and particles, particles and beads and beads and beads. There are three different types of forces influence on particles including conservative force or $\vec{f}_{i j}^{C}$ with polymer force or $\vec{F}_{P, i}$, the dissipative force or $\vec{f}_{i j}^{D}$ and the random force $\vec{f}_{i j}^{R}$ [39-44].

$$
\begin{aligned}
& \vec{f}_{i j}^{C}=\left\{\begin{array}{cc}
a_{i j}\left(1-r_{i j} / r_{C}\right) \hat{r}_{i j} & r_{i j}<r_{C} \\
0 & r_{i j} \geq r_{C}
\end{array}+\vec{F}_{P, i}\right. \\
& \vec{F}_{P, i}=-K\left(r_{i, i \pm 1}-r_{i, i \pm 1}^{e q}\right) \hat{r}_{i, i \pm 1}=\vec{F}_{P, i} \\
& \vec{f}_{i j}^{D}=-\gamma \omega^{D} r_{i j}\left(\hat{r}_{i j} \cdot \vec{v}_{i j}\right) \hat{r}_{i j} \\
& \vec{f}_{i j}^{R}=-\sigma^{R} \omega^{R} r_{i j} \theta_{i j} \hat{r}_{i j}
\end{aligned}
$$

Where $a_{i j}$ is the repulsion between particles and thin layer of soft material (membrane), $r_{i j}$ is the distance between two particles with velocity of $\vec{v}_{i j}$ in cut off radios $r_{C}, K$ is harmony constant coefficient between particles of thin layer of soft material, $\gamma, \sigma^{R}, \omega^{D}$ and $\omega^{R}$ are the strength parameters and weight function of dissipative and random force respectively. Simulation condition is reported in Table 1 and detailed on this method is refer to ref $[40,41]$.

Figure $2 \mathrm{~A}$ shows the inflation process by increasing the pressure over time. As it is illustrated, after short time, there are no changes and equilibrium between pressure of fluid and force of soft material is resulted. Two essential parameters including dimensionless pressure $(\bar{P}=A \rho ; \mathrm{A}$ is a coefficient and $\rho$ is density) and harmony bond constant ( $K$ ) influence on amount of displacement which the nonlinear behavior of them are depicted in Figure 2 (B-a) and Figure 2 (B-b). By increasing the density or dimensionless pressure, a conspicuous growth of membrane, displacement is formed while with raising the $K$-parameter, a remarkable drop is observed. By increasing the dimensionless pressure, particles implement more pressure (more summation of $\vec{f}_{i j}^{C}$ ) on membrane and higher displacement is observed while by enhancing the $K$-parameter, the membrane resist more against displacement.

Table 1: Input condition for simulation of AM using DPD numerical code.

\begin{tabular}{|l|l|l|l|l|l|l|}
\hline Variables & $\begin{array}{l}a_{i j}[43] \\
\text { (Coefficient of different } \\
\text { particles interactions) }\end{array}$ & $\begin{array}{l}a_{i j}[43] \\
\text { (Coefficient of same } \\
\text { particles interactions) }\end{array}$ & $\begin{array}{l}\text { Number } \\
\text { of } \\
\text { particles }\end{array}$ & $\begin{array}{l}\text { Time } \\
\text { step }\end{array}$ & $\begin{array}{l}\text { Harmony } \\
\text { bond } \\
\text { constant } \\
(K)\end{array}$ & $\begin{array}{l}\text { Number of } \\
\text { beads }\end{array}$ \\
\hline Value & 3 & 10 & 4000 & 0.001 & $500-5000$ & 50 \\
\hline
\end{tabular}



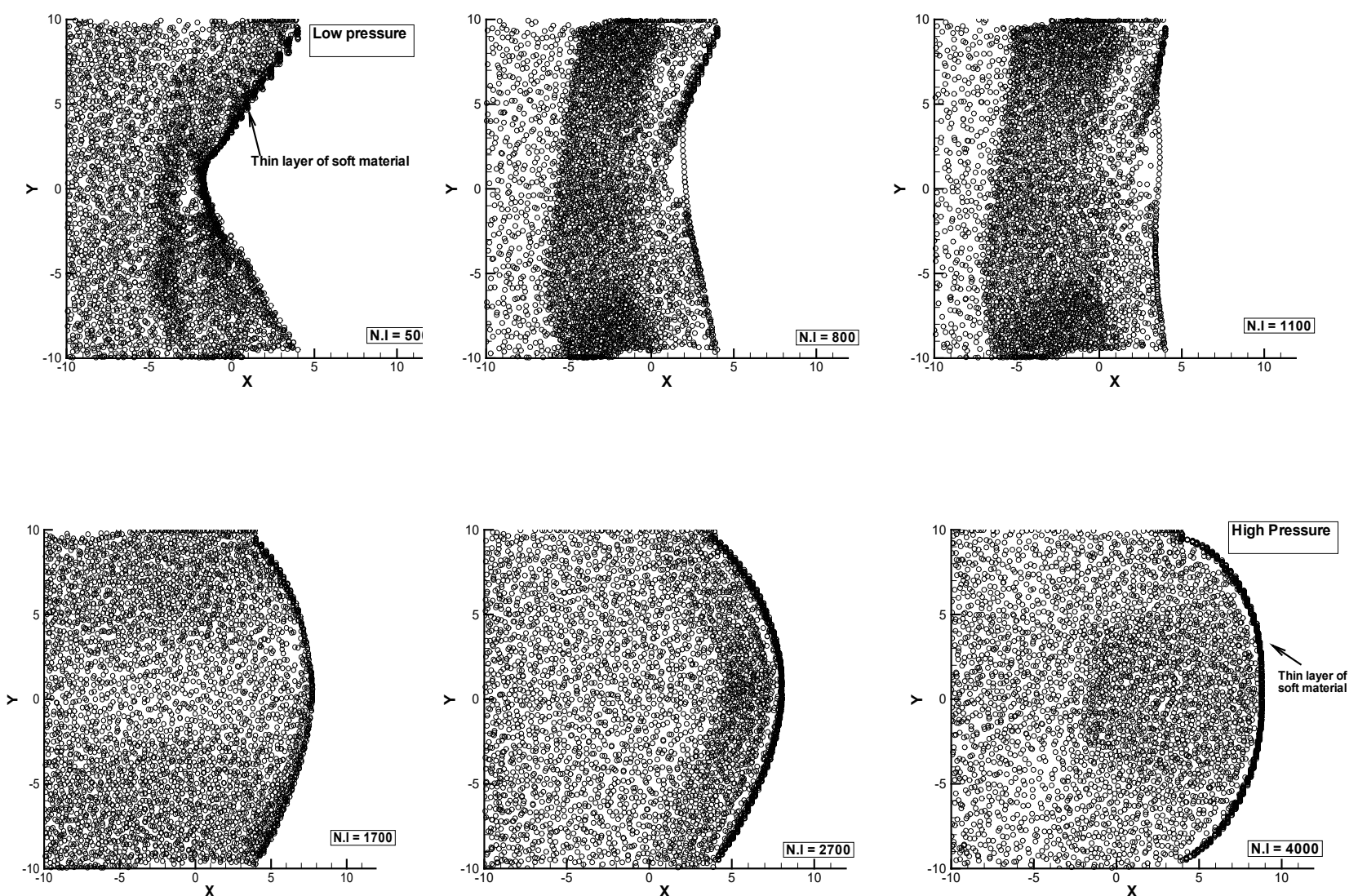

(A)

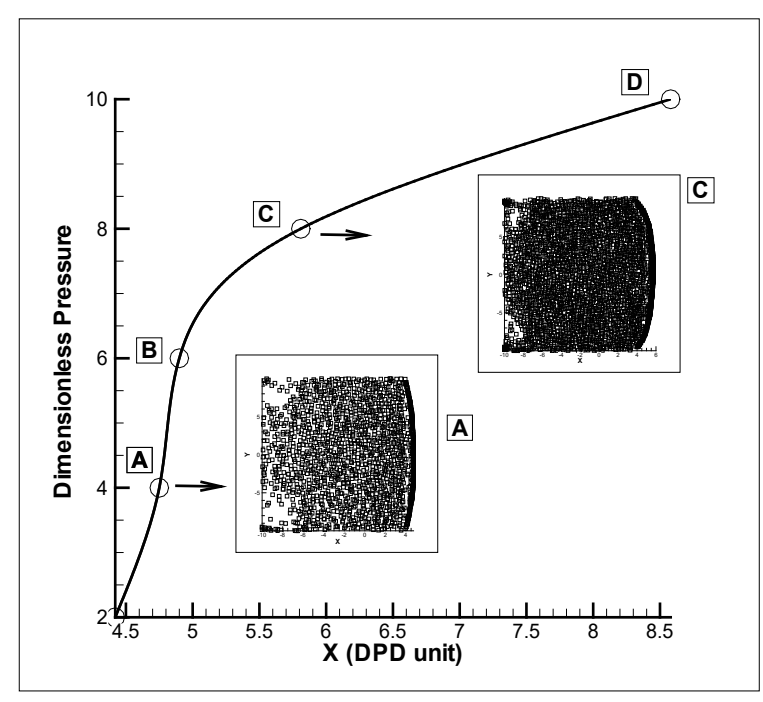

(B-a)

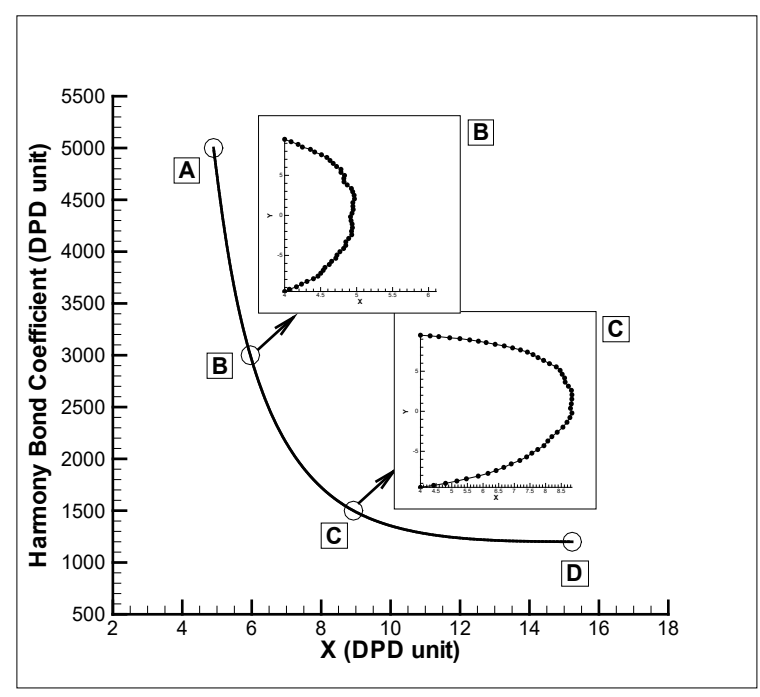

(B-b)

Figure 2: DPD Simulation of artificial myosin. (A) Inflation of soft martial over number of time steps or iteration (N.I) for dimensionless pressure 10 and $K=5000$; (B) Nonlinear trend of different dimensionless pressuresdisplacement in $\mathrm{x}$-direction for $K=5000$ (B-a) and variation of harmony bond coefficients for dimensionless pressure of $6(B-b)$.

Behavior of particles pressure and inflation of membrane emphasis on nonlinear trend of displacement, depended on condition, and also, by increasing the pressure, the simultaneous inflation is about to happen and these trends play important role on fast and convenient displacement. This result directly shows that by increasing the flow rate and higher chemical reaction (more dimensionless pressure), more or faster reaction may be occurred nonlinearly. Thus, the numerical simulation shows 


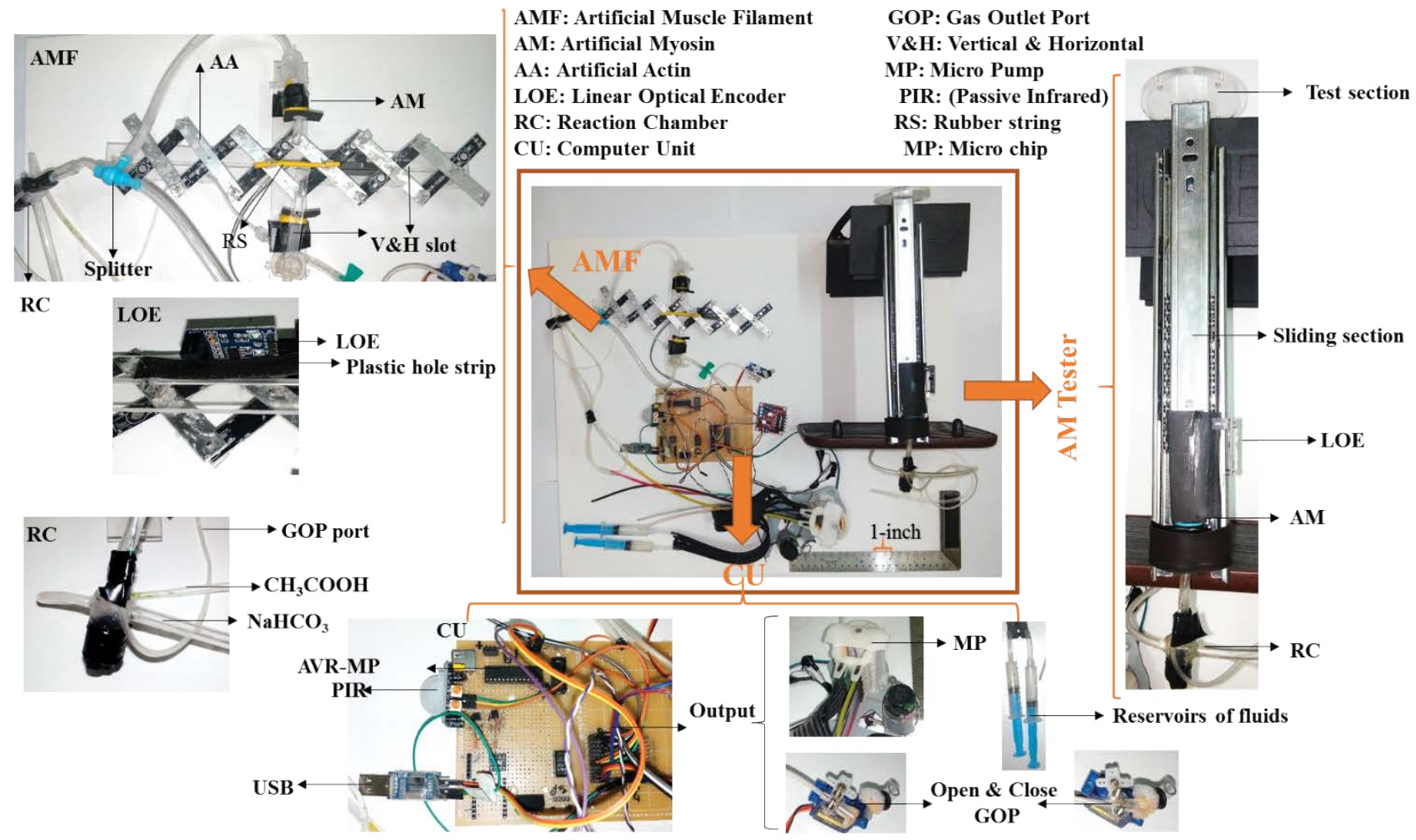

(A)

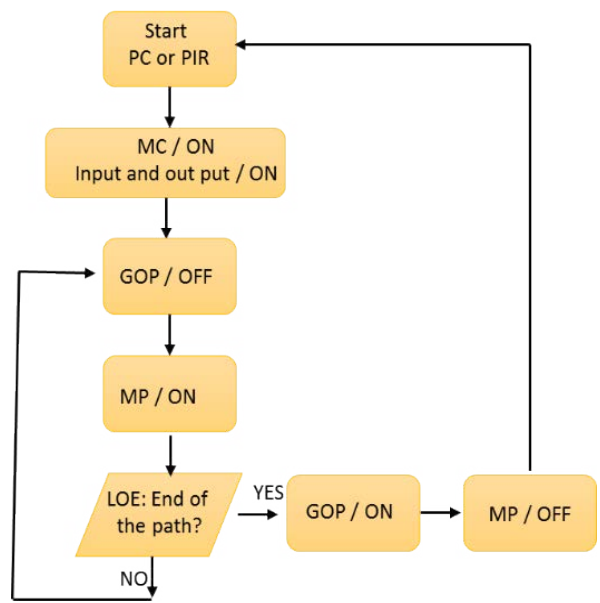

(B)

Figure 3: Experimental setup for $A M$ and $A M F$ tests and schematic diagram of $C U$. (A) All equipment for tests of AM (AM tester), AMF and CU (AVR-MC) with related components ( $L O E, R C, V$ \& $L$ slot on the main structure of AMD, GOP, MP and fluids reservoirs); (B) Flow chart of microchip programing between inputs (LOE, PC or PIR) and outputs (GOP, MP).

an expansion phenomenon which gives insight into the soft material.

\section{Experimental setup and AMF test cases}

In addition to numerical simulation, some experimental tests are essential to be clearly illustrated all aspects of applicability of the proposed method. For testing the proposed method, although the manufacturing of $A M, A A$ and consequently AMF should be surly followed but constructing and preparing the tester of AM and other related components for controlling the fluid flows are crucial.

Figure 3 totally shows the equipment used for this experiment. According to proposed mechanism, based on filament sliding theory, the AMF in Figure 3 consists of $A M, A A$, linear optical encounter (LOE), internal structure of horizontal and 
vertical slot and reaction chamber (RC). AM tester is an applicable designed device which it can measure amount of displacement, due to inflation of $A M$, over time. AM tester also equips with LOE to send signal to $\mathrm{CU}$ for processing the amount and trend of displacement in different loading condition. CU briefly involves of some inputs; USB port or PIR sensor (Passive infrared sensor) as a starting comment and LOE for detection of displacement, and outputs including signal of Pulse-width modulation (PWM) to driver of DC motor (micropump) for pumping fluids based on the comment from PC, signal to servo motor as a gas outlet port (GOP), activating end of the traveling path. Central process or AVR (AT MEGA 8), based upon the flowchart in Figure 3 , by receiving the inputs and defined conditions will send signal to outputs. The process of activation in the programed microchip is that by receiving the start signal from PC computer (entering the different conditions) or movement of body from PIR sensor (repeating the experiment), the comment will send to servo motor to close the GOP and then output signal for running the micro pump will be active to pump the fluids in reaction chamber. Receiving signal from LOE is simultaneously controlled by microchip, as a feedback line, to avoid excessive actuation of AM. In the end of traveling path by countering the small holes in the LOE and sending signal to AVR, the servo discharge port will be opened by GOP and the AM and AA will be returned to original position by deflation of soft material and rubber string respectively.

The control process of inflation/deflation and consequently actin movement were inspired by nature, which by sending signal from CNS (comment from $\mathrm{PC}$ computer), releasing the $\mathrm{Ca}^{+2}$ (pumping the fluids) then changing the ATP to ADP, transferring the energy (chemical reaction in reaction chamber) and forming the cross bridge, the actin will be pulled by myosin (forming cross bridge and pushing the $A A$ via $A M$ ) and also by collecting the $\mathrm{Ca}^{+2}$ and losing of energy (opening the discharge port and releasing the pressurization), the filament will return to relax [33] (AMF will be returned to initial).

As shown in Figure 4, AM tester is designed and constructed for test of AM (soft material) performance. The AM tester consists of artificial myosin, sliding mechanism and linear optical encoder (LOE). Feeding system flows sodium bicarbonate solution with water and acetic acid and high pressure gas from reaction of them inflates the myosin and by changing the AM volume, $\mathrm{AM}$ pushes the sliding mechanism upwards, amount of displacement is calculated by LOE. Displacement of $10 \mathrm{~mm}$ through $3 \mathrm{~s}$ is shown in Figure 4A under $247 \mathrm{~g}$ weight and $2 \mathrm{~mL} / \mathrm{s}$ fluids flows at one time operation. Amount of displacement and the weight that can be carried over time, would be two essential quantities which are plotted in the Figure $4(B-a)$ and Figure 4 (B-b) respectively. It is worthwhile to mention that by increasing the flow rate and more chemical reaction, more gas will be released and based on the Eq. (1-4), summation of $\vec{f}_{i j}^{C}$ raise and extra force has nonlinear trend. The net weight of moving part of sliding mechanism is $125 \mathrm{gr}$ and amount of allowable displacement is $10 \mathrm{~mm}$ for this study (swelling ration of 10). According to experimental data, by enhancing the flow rate of fluids remarkable nonlinear quick response time is observed with less than 10 percent error in the repeat experiences for 3 times. Also, the plot of Figure 4 (B-b) reports the displacement of sliding mechanism over time which rate of AM expansion is influenced from different flow rate of fluid. Trend of different extra weights on AM is indicated in the Figure 4 (C-a). As it is expected by increasing the weight, more time consumes to complete the displacement. Based on the results, $15 \mathrm{~mm}$ diameter of $A M, 2 \mathrm{~mL} / \mathrm{s}$ flow of fluids in one movement, it can carry $247 \mathrm{~g}$ weight in just $3 \mathrm{~s}$ is reported as applicable results for next section. Furthermore, the displacement over time for constant flow rate of $2 \mathrm{~mL} / \mathrm{s}$ and different weights are presented in the Figure 4 (C-b). It is noticeable that, by keeping constant flow rate, heavy weights shape more nonlinear behavior over time (very slow motion). It can be realized that small soft material and fluid in high pressure are enough to change chemical reaction potential to mechanical displacement which can carry 625 gr while AM with $5 \mathrm{~mL}$ chemical materials just have almost $12 \mathrm{~g}$ weight and will be significant option for fabrication of an AMF.

According to proposal method and results, the AM is implemented in the scissor mechanism with accompany of other components such as feeding system, computer unit and LOE. The large laboratory model of an AMF with experimental results is presented in Figure 5. Displacement of AMF, by actuation of $A M$ volume and pushing the scissor mechanism or AA on a vertical and consequently horizontal slot path to transient time is presented in Figure $5 \mathrm{~A}$. The maximum displacement of $A A$, 


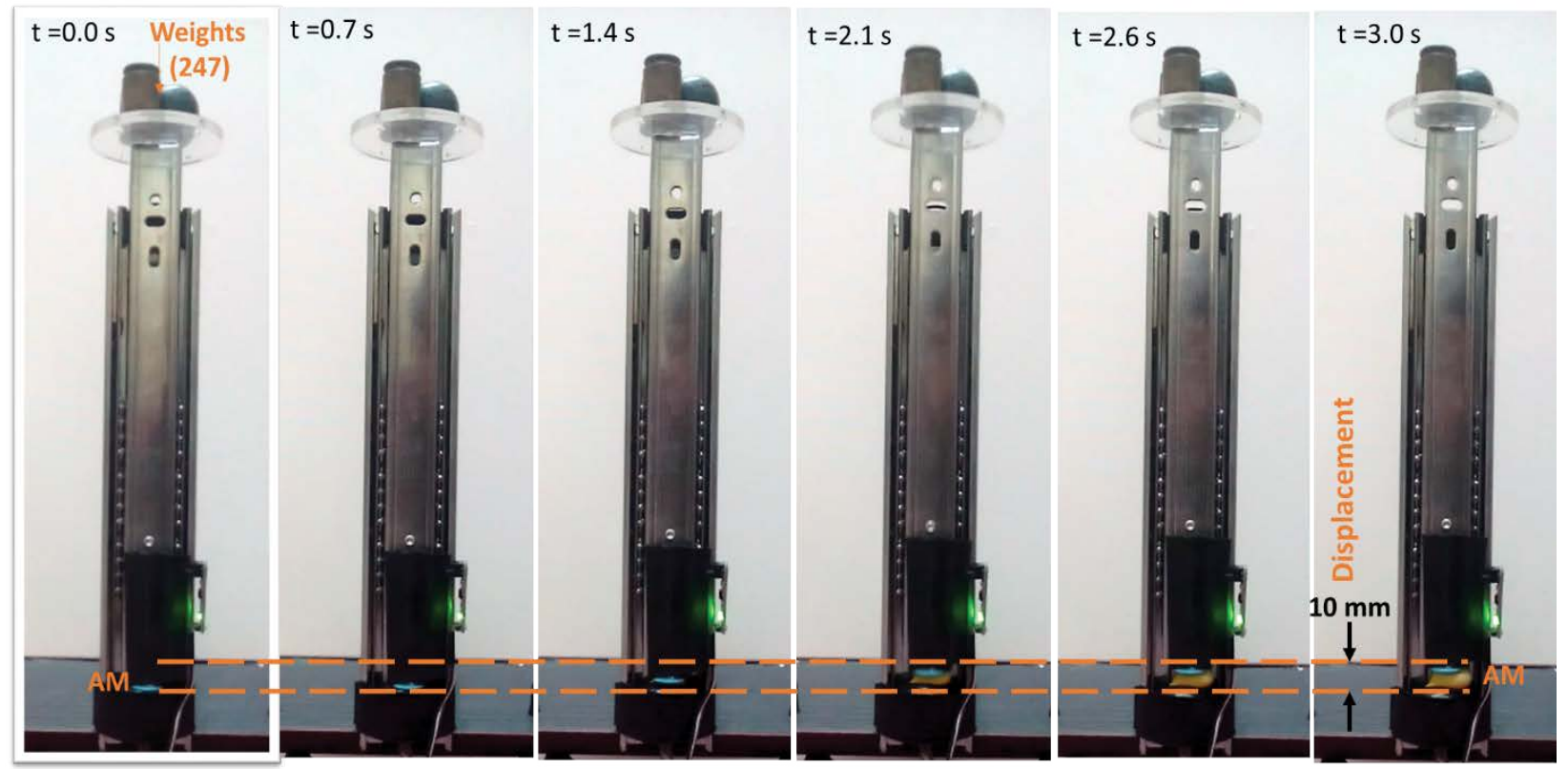

(A)

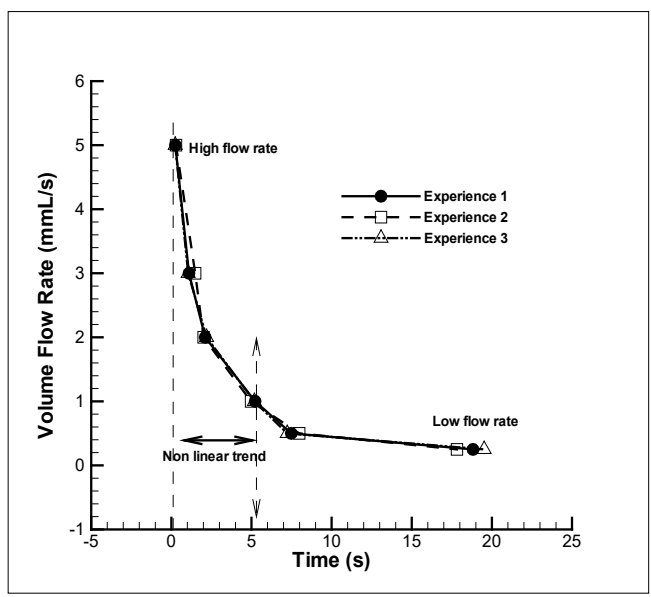

(B-a)

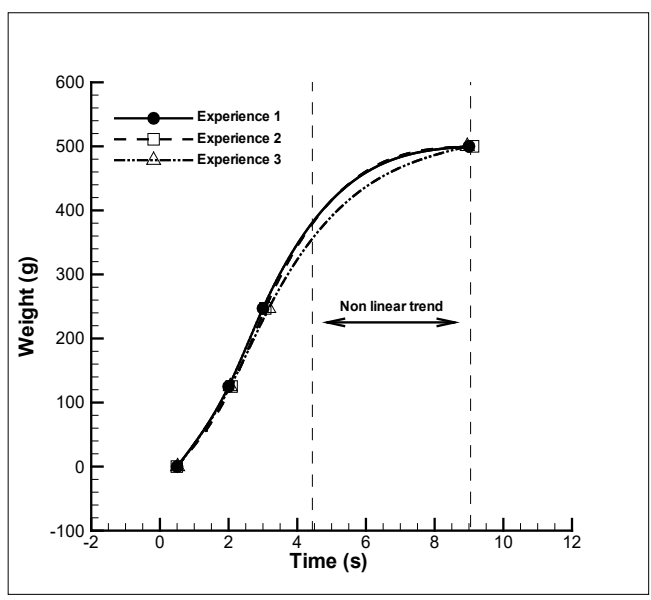

(C-a)

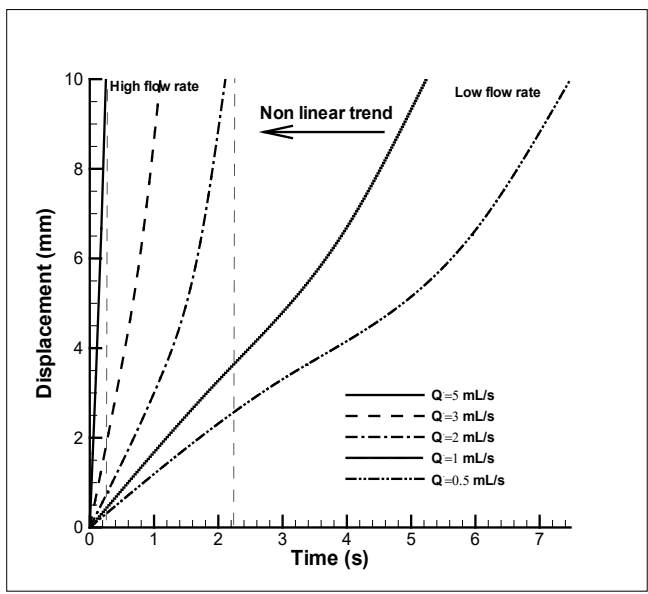

(B-b)

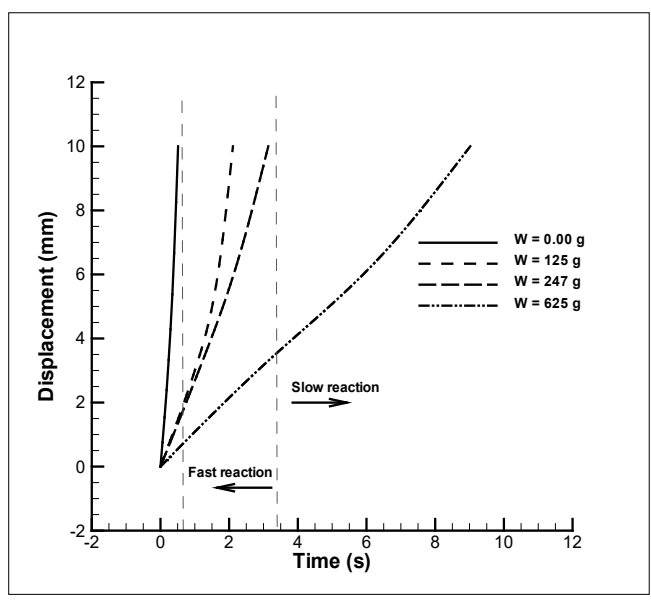

(C-b)

Figure 4: Test of $A M$ performance using $A M$ tester. (A) Inflation of $A M$ under $247 \mathrm{~g}$ weight compared to passing the time. (B-a) The relation of response time and AM-volume flow rate; (B-b) Comparison of AM displacement by changing the volume flow rate over time; Increasing of traveling time step by reduction of volume flow rate; (C-a) nonlinear trend of response time of AM by increasing the load; (C-b) Comparison of AM displacementtime to constant volume flow rate of $2 \mathrm{~mL} / \mathrm{s}$ under different loading condition. 

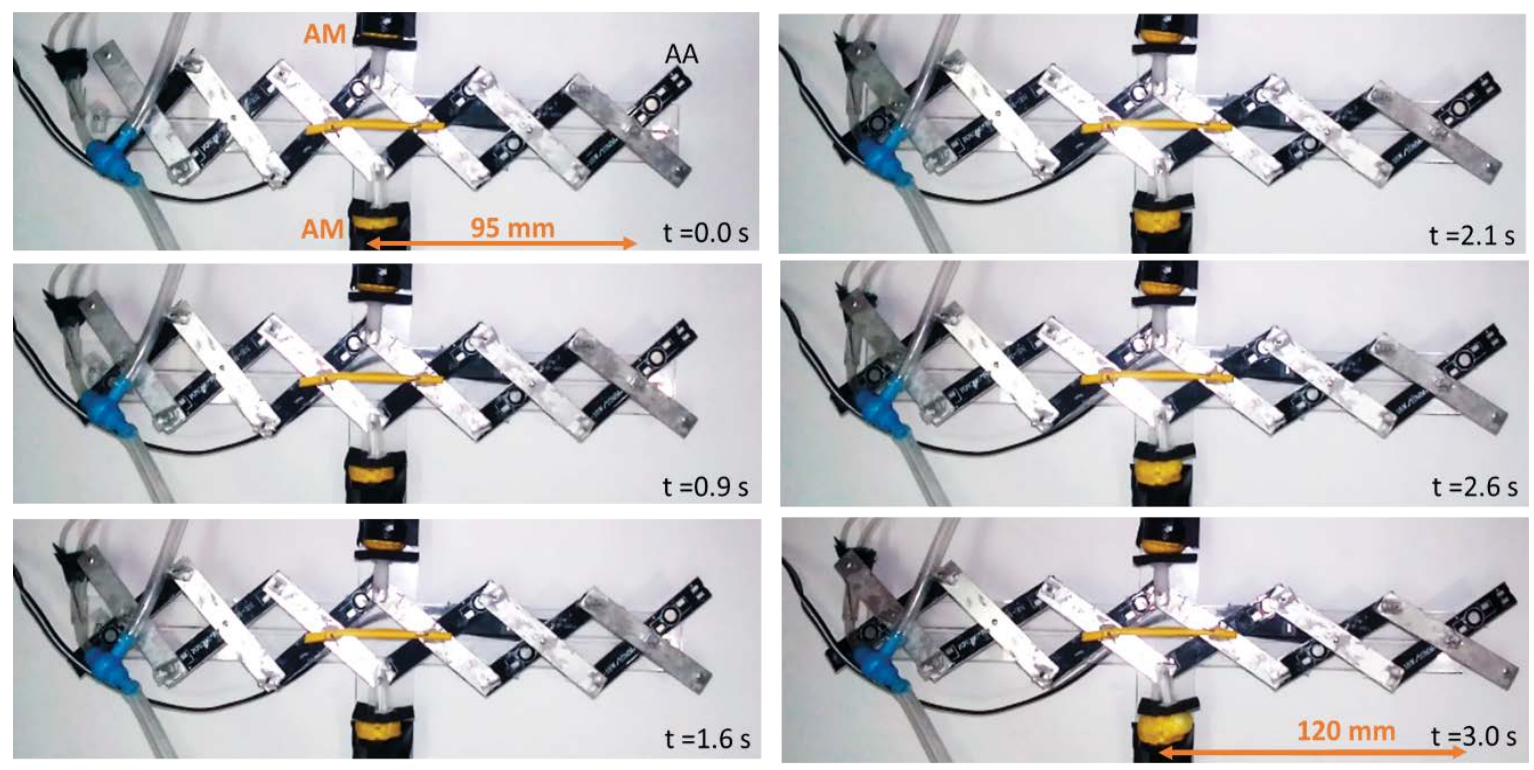

(A)

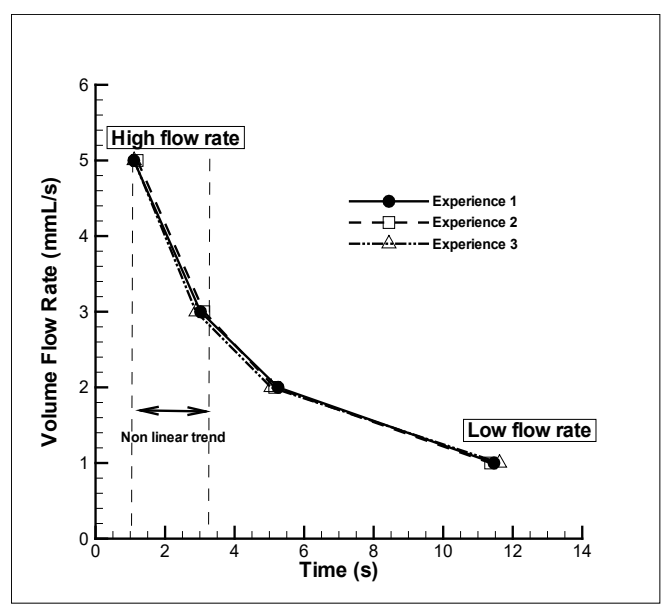

(B-a)

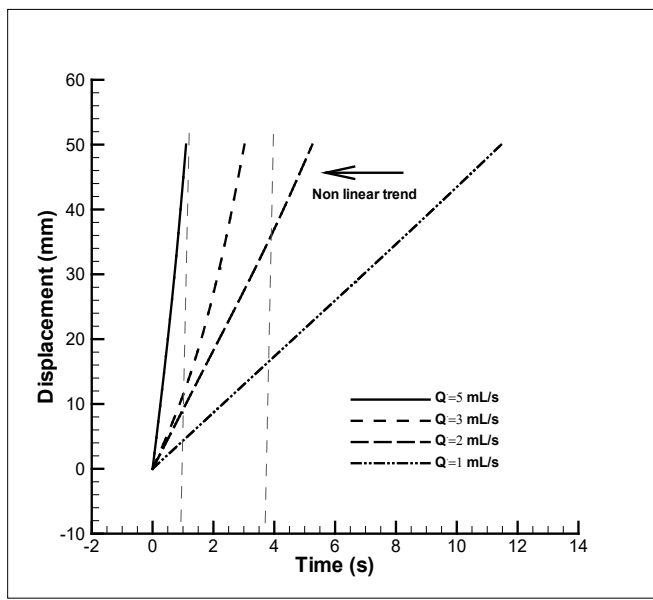

(B-b)

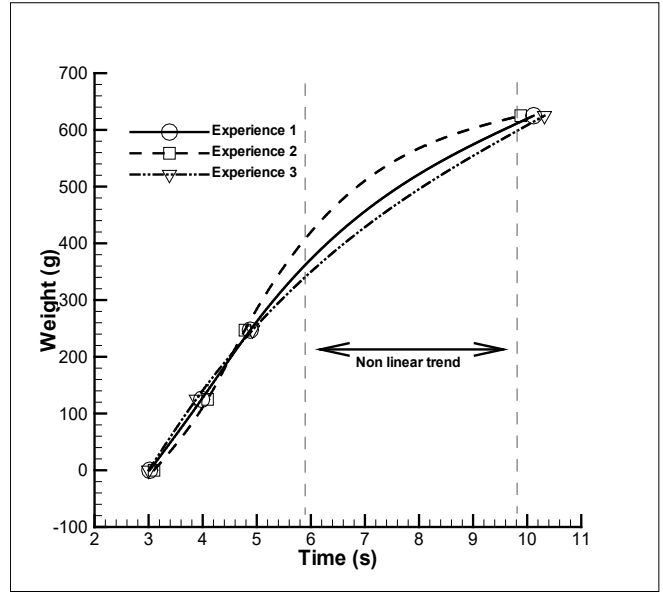

(C-a)

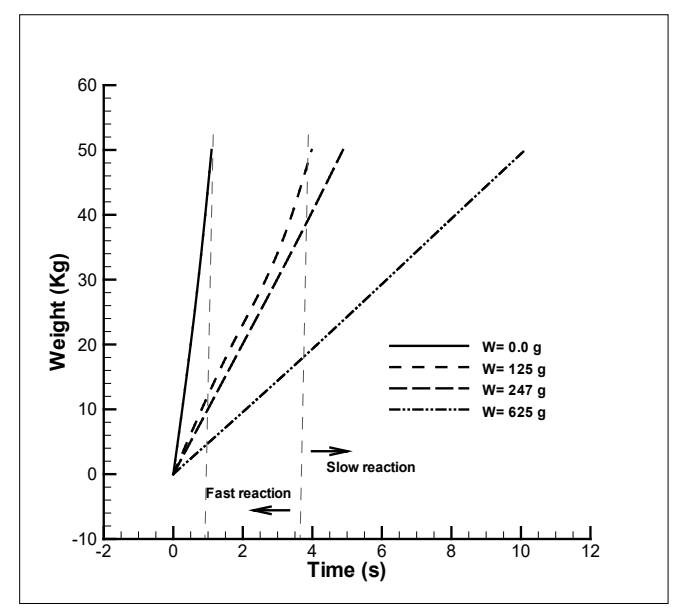

(C-b)

Figure 5: Expansion of AMF. (A) Inflation of AM, movement of actin and consequently expansion of AMF compared to passage of time; (B-a) Slow response time of AMF by decreasing the volume flow rate; (B-b) Linear behavior of AMF displacement by changing the volume flow rate over time; Increasing of time traveling by reduction of volume flow rate; ( $C$-a) Trend of weight on AMF response time; (C-b) Comparison of AMF displacement versus time for different loading condition and constant flow rate of $3 \mathrm{~mL} / \mathrm{s}$. 
by setting the 5 hinged segments and inflation of both AMs equal to $10 \mathrm{~mm}$, is almost $50 \mathrm{~mm}$ with total weight of $60 \mathrm{~g}$ and $A M$ diameter of $15 \mathrm{~mm}$ (AMF swelling ration of 0.26). Relaxation of AMF is performed as soon as gas pressure is evacuated out and AM will be flatted. One of the noticeable advantages of soft materials compared to rigid actuator will be fast response in pressurization or depressurization process while linear piston type actuator, because of large friction between piston and cylinder for avoiding any leakage, needs more time to response or high power consumption and advanced control system is essential to control snap response.

The performance of proposed AMF is investigated in Figure $5(B-a)$ to Figure $5(C-b)$. At the first, as can be expected, raising the flow rate or higher chemical reaction would influence on faster response, due to higher pressure of produced gas, (Figure $5(B-a)$ ), for example, although by flow of $3 \mathrm{~mL} / \mathrm{s}$ fluids in the reaction chamber in one operating, around the 3 second would take for $50 \mathrm{~mm}$ displacement under load of $125 \mathrm{~g}$ but higher or lower fluids flow have potential to remarkably change the response time, which depend on application. By enhancing more chemical reaction and consequently higher conservative forces or $\vec{f}_{i j}^{C}$ (see Eq. 1-4), more fluid particles collide the soft material or AA, resistant force of soft material or $\vec{F}_{P, i}$ is less compared to total forces of particles and volume changes of soft material or displacement of AA will be identified almost simultaneously for high flow rate condition. Figure $5(B-b)$ plots displacement of AMF over time for different flow rate. It is obvious that due to friction in the scissor mechanism joints, almost a linear trend is govern especially for lower flow rate. Under loading condition for flow rate of $3 \mathrm{~mL} / \mathrm{s}$ in one action, response time for higher loading (more than $250 \mathrm{~g}$ ) nonlinearly decreases which it is sign of need for higher flow rate and fair movement is resulted for $125 \mathrm{~g}$ or $247 \mathrm{~g}$ weight (Figure 5 (C-a). Amount of transfer of AA by passage of time under loading condition is depicted in Figure 5 (C-b) which, as expected, a linear responses is resulted especially for higher loading condition.

It is worthwhile to be recognized that scissor mechanism provides large displacement to compensate low displacement of AM which AM has stunning ability to response fast or slow as much as it is necessary using controlling the flow rate of reaction of sodium bicarbonate-acetic acid and gas output port. Combination of soft and hard materials gives opportunity to use advantages of them in various applications. Also, due to simple constriction of them, the proposed method can be implemented to desired size and modularization of them will be feasible. Figure 6 show a small laboratory AFM model similar to large one with 5 $\mathrm{mm}$ diameter of AM, 2 jointed segments or $40 \mathrm{~mm}$ compressed $\mathrm{AA}$ and ability to expand $10 \mathrm{~mm}$ with total weight of $9 \mathrm{~g}$. By flowing $1 \mathrm{~mL} / \mathrm{s}$ fluids in the reaction chamber in one operation, around the 1 second would be response time to form stretching mechanism (Figure 6A). We also propose modulation of AMF seriously for formation of myofibril, parallel them as a fiber and consequently parallel fiber will provide applicable artificial muscle based on the natural principle (Figure 6B). In Table 2, the present method is compared with other methods from some aspects of swelling/inflation ration, response time, strain-actuation stress, advantages and disadvantages of methods. It is clear that present method can perform displacement close to natural muscle due to mimicking and following some patterns from nature.

\section{Conclusion}

In this paper, new proposed AMF (artificial muscle filament) was presented inspired by nature and considering possibility of industrial manufacturing. An AM (artificial myosin) or soft material and AA (artificial actin) or scissor mechanism were two main components of AFM and reaction flow between $\mathrm{CH}_{3} \mathrm{COOH}$ and $\mathrm{NaHCO}_{3}$ was controlled by computer unit, LOE (linear optical encoder) and gas outlet port (GOP) which the energy from reaction produced enough controlled gas to inflate the AM and it displaced AA. At the first, AM was exemplified by DPD (dissipative particle dynamics) numerical simulation in which the results show that by increasing the dimensionless pressure or decreasing the harmony bond coefficient the displacement of membrane will nonlinearly enhance. Also from experimental tests (AM tester), by increasing the rate of flow, nonlinear trend for $10 \mathrm{~mm}$ displacement of $247 \mathrm{~g}$ weight were observed which for and $2 \mathrm{~mL} / \mathrm{s}$ flow rate, respond time was taken around 3 second. Proposed AFM provided $50 \mathrm{~mm}$ displacement by $3 \mathrm{~mL} / \mathrm{s}$ flow rate in the 3 second using combination of hard material (scissor mechanism) and soft material (natural rubber as AM). The mentioned 

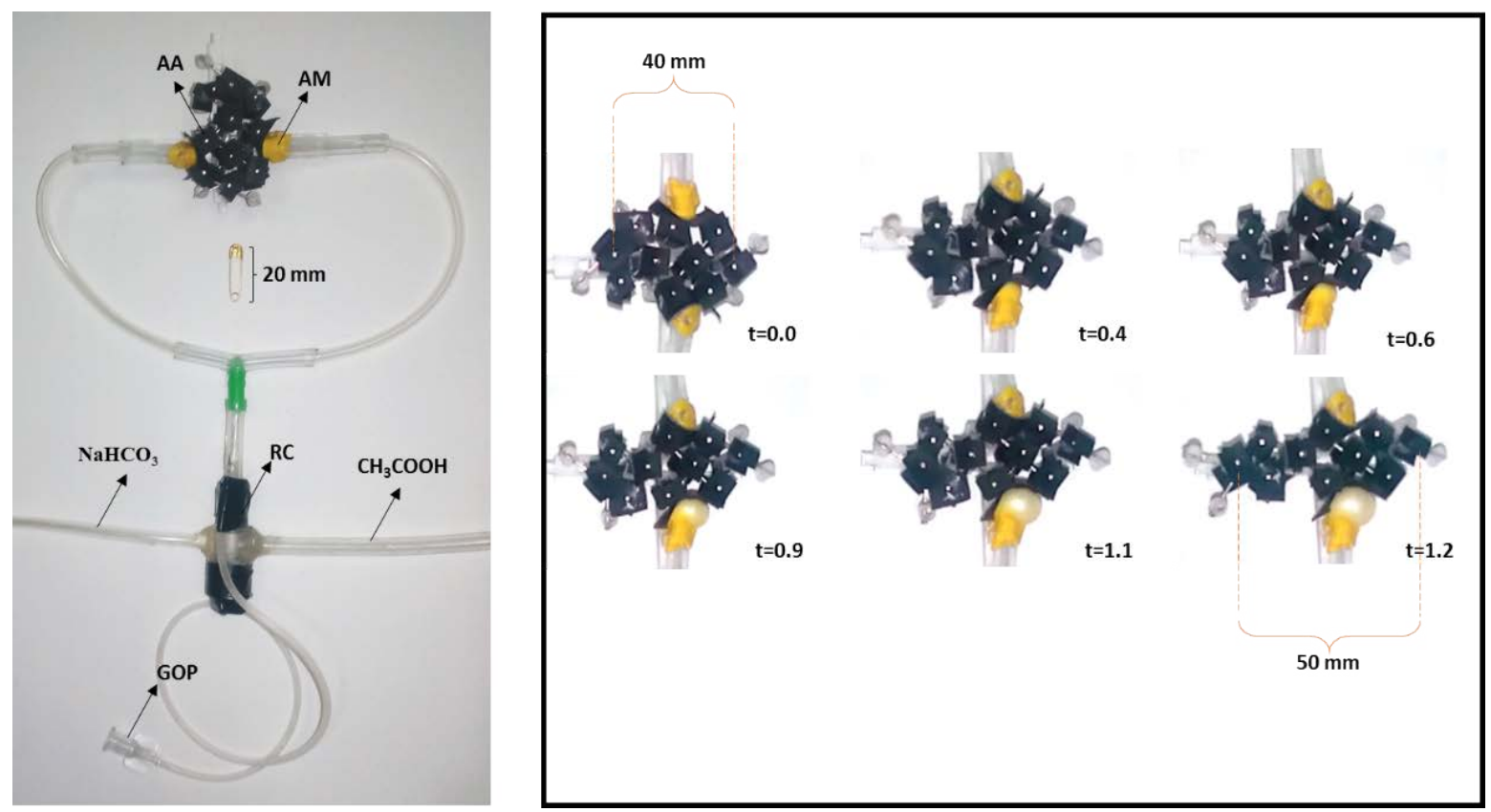

(A)

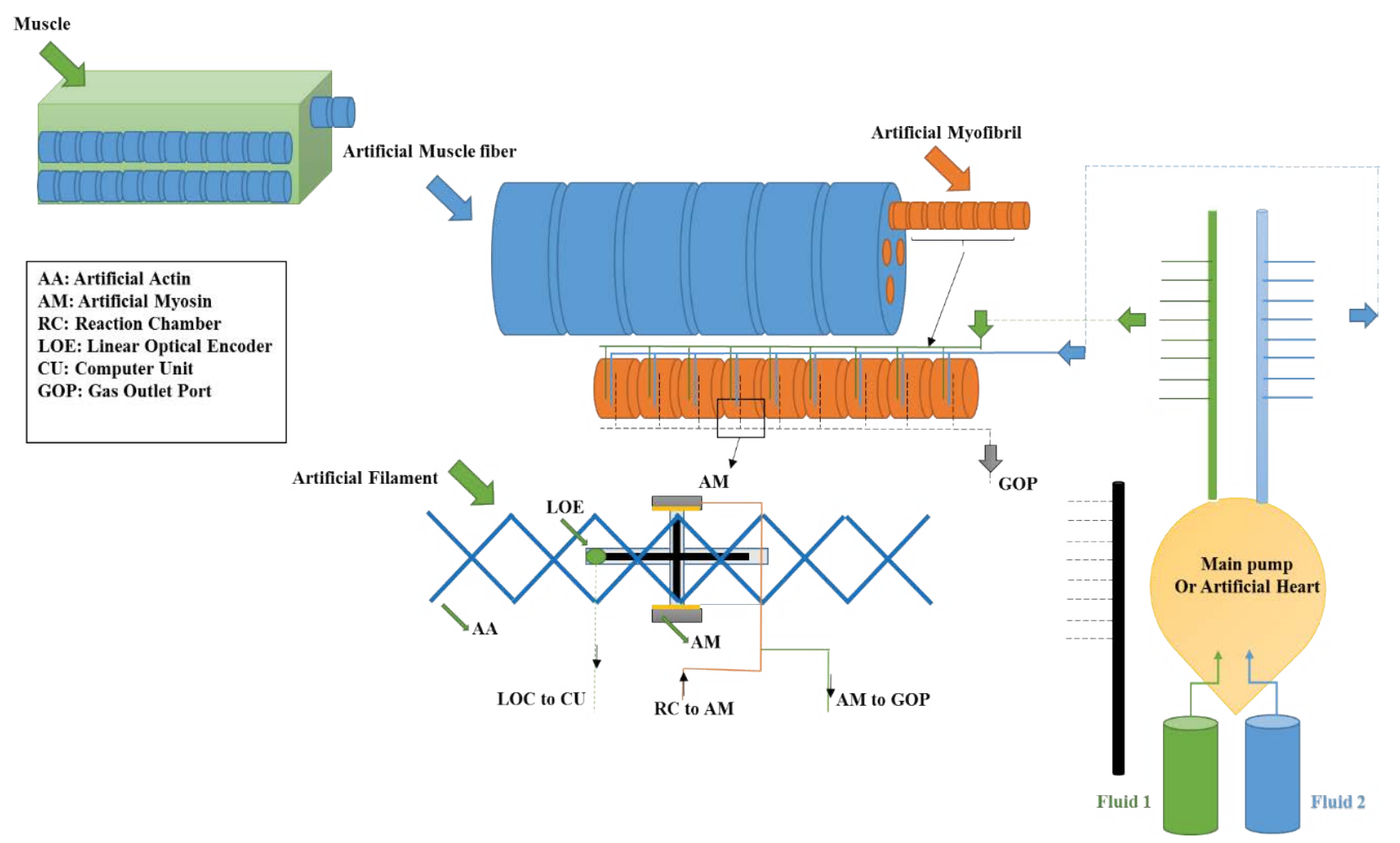

(B)

Figure 6: Fabrication of small AMF and breakdown structure of proposed artificial muscle, from artificial muscle fiber to artificial muscle filament. (A) Miniaturization of proposed AMF and related component. Expansion of AMF compared to time with flow rate of $1 \mathrm{~mL} / \mathrm{s}$ (one operating step) and displacement of $10 \mathrm{~mm}$; (B) Modularization of AMF to artificial muscle. Series connection of AMF and formation of artificial myofibril and parallel combination of artificial myofibril to be constructed an artificial muscle fiber and likewise, parallel connection of muscle fiber and formation of artificial muscle. 
Table 2: Comparison of present artificial muscle method with different methods.

\begin{tabular}{|c|c|c|c|c|}
\hline Type & Swelling ratio & $\begin{array}{l}\text { Response } \\
\text { time (s) }\end{array}$ & $\begin{array}{l}\text { Strain } \\
\text { (\%)-Actuation } \\
\text { stress (Mpa) }\end{array}$ & Ref \\
\hline Present method & $0.1-1$ & $0.5-3$ & $\begin{array}{l}0.3 E+02 \\
0.4 E+00\end{array}$ & - \\
\hline Real muscle & $0.1-1$ & $0.5-3$ & $\begin{array}{l}0.39 E+02 \\
0.34 E+00\end{array}$ & [34] \\
\hline Pneumatic A. M. & $1-1.5$ & $0.5-3$ & $\begin{array}{l}0.11 E+03 \\
0.11 E+01\end{array}$ & [34] \\
\hline Hydrogels (PH) & $0.2-10$ & $60-300$ & $0.17 E+03$ & {$[34,45]$} \\
\hline Hydrogels (Temp.) & $0.2-1.5$ & $300-1200$ & $0.13 E+01$ & {$[34,46]$} \\
\hline Hydrogels (Electricity) & $0.3-47$ & $7-1843$ & to & {$[34,47]$} \\
\hline Hydrogels (Magnetic) & $1.06-1.32$ & - & $089 \mathrm{~F}$ & {$[34,48]$} \\
\hline Hydrogels (light) & $0.1-1$ & $1000 \mathrm{~s}$ & $0.14 \mathrm{E}+01$ & {$[18,34]$} \\
\hline Electroactive polymers & $0.1-1$ & $1-3$ & $\begin{array}{l}0.10 E+03 \\
0.38 E+00\end{array}$ & {$[9,34]$} \\
\hline Shape memory alloys & $0.1<$ & $1-10$ & $\begin{array}{l}0.72 E+01 \\
0.69 E+03\end{array}$ & {$[34,49]$} \\
\hline Elastomer & $0.1-1$ & $160>$ & $\begin{array}{l}0.10 E+03 \\
0.13 E+01\end{array}$ & [34] \\
\hline $\begin{array}{l}\text { Hydraulically amplified } \\
\text { self-healing electrostatic } \\
\text { (HASEL) }\end{array}$ & $0.1-1$ & $0.5-3$ & $\begin{array}{l}0.16 E+02 \\
0.3 E+00\end{array}$ & {$[34,50]$} \\
\hline Type & Adv. & \multicolumn{2}{|l|}{ Dis adv. } & Ref \\
\hline Present method & $\begin{array}{l}\text { Swelling ration and response time can } \\
\text { be adjusted according to demand } \\
\text { Without need high voltage or } \\
\text { electricity for actuation } \\
\text { Low weight and high output power } \\
\text { Act like human muscle }\end{array}$ & \multicolumn{2}{|c|}{$\begin{array}{l}\text { Need sub system to be actuated } \\
\text { such as GOP }\end{array}$} & - \\
\hline Pneumatic A. M. & $\begin{array}{l}\text { Adv. similar to present work but need } \\
\text { electricity for actuation }\end{array}$ & \multicolumn{2}{|c|}{$\begin{array}{l}\text { High weight (with account of } \\
\text { compressor) } \\
\text { Noise pollution }\end{array}$} & [11] \\
\hline Hydrogels & Can be extended to different modes & \multicolumn{2}{|c|}{ Long response time } & {$[18,45-48]$} \\
\hline Electroactive polymers & Single self-contained mechanism & \multicolumn{2}{|c|}{ Need high voltage } & [9] \\
\hline Shape memory alloys & Single self-contained mechanism & \multicolumn{2}{|c|}{ Need heating and cooling } & [49] \\
\hline Elastomer & Single self-contained mechanism & \multicolumn{2}{|c|}{ Long response time } & [34] \\
\hline HASEL & $\begin{array}{l}\text { Act like human muscle } \\
\text { Single self-contained mechanism }\end{array}$ & \multicolumn{2}{|c|}{ Need high voltage } & [50] \\
\hline
\end{tabular}


proposal showed conspicuous potential to manufacture in desired size, power and response time based on the intended application. Furthermore, miniaturization of AMF was presented which with flow rate of $1 \mathrm{~mL} / \mathrm{s}$, the expansion rate of $8.3 \mathrm{~mm} / \mathrm{s}$ was resulted. Also, proposal future artificial muscle based on the modularization of AMF was presented. The proposed mechanism by employing sliding theory of filament and mimicking nature, lightness, low volume, very cheap, expandable to micro scale constriction using $3 \mathrm{~d}$ printer in future and capability of modulation of AMF and other features may be significant place for future applications and next research, we will focus on one of the AMF and artificial muscle applications.

\section{Data Availability}

The authors declare that the data supporting the findings of this study are available within the paper and additional data on methods used are available upon reasonable request.

\section{References}

1. Hall JE (2015) Guyton and hall textbook of medical physiology (Guyton Physiology). (13 ${ }^{\text {th }}$ edn), Saunders, Philadelphia, USA.

2. Singth $H$, Singh $L$, Yadav $M$ (2018) Fundamentals of medical physiology, ( $8^{\text {th }}$ edn), Elsevier, Amsterdam, Netherlands.

3. http://www.lamission.edu/lifesciences/lecturenote/aliphysio1/muscles.pdf

4. Rus D, Tolley MT (2015) Design, fabrication and control of soft robots. Nature 521: 467-475.

5. Tolley MT, Robert FS, Bobak M, Kevin CG, Michael W, et al. (2014) A resilient, untethered soft robot. Soft Robot 1: 213-223.

6. Spiers A, Khan SG, Herrmann G (2016) Biologically inspired control of humanoid robot arms. Robust and Adaptive Approaches, ( $1^{\text {st }}$ edn), Springer, Germany.

7. Park SJ, Park CH (2019) Suit-type wearable robot powered by shape-memory-alloy-based fabric muscle. Scientific Reports, 9157.

8. Wu R, Soutis C, Zhong S, Filippone A (2016) A morphing aerofoil with highly controllable aerodynamic performance. Aeronautical Journal New Series 121: 1-19.

9. Yang $T$, Youhua $X$, Zhen $Z$, Yiming L, Guorui L, et al. (2018) A soft artificial muscle driven robot with reinforcement learning. Scientific Reports, 14518.

10.Wang L, Qu X, Meng Q, Yuan P, Wang M (2002) Mo- tor driving leg design for bionic crab-like robot. Journal of Marine Science and Application 1: 72-77.

11.Abdellatif A, Alfayad S, Hildebrandt AC, Ouezdou FB, Mechbal N, et al. (2018) Development of a new hydraulic ankle for HYDROïD humanoid robot. Journal of Intelligent \& Robotic Systems 92: 293-308.

12. Bai K, Luo M, Li T, Wu J (2018) The impulse excitation joint servo drive design and adaptive backstepping control of humanoid robots. Journal of Bionic Engineering 15: 114-125.

13.Hwang T, Frank Z, Neubauer J, Kim KJ (2019) High-performance polyvinyl chloride gel artificial muscle actuator with graphene oxide and plasticizer. Scientific Reports 9: 9658.

14.Yeom SW, Oh K (2009) Biomimetic jellyfish robot based on ionic polymer metal composite actuators. Smart Mater Struct 18: 085002.

15.Guo SX, Fukuda T, Asaka K (2003) A new type of fish-like underwater microrobot. IEEE/ASME Trans Mechatron 8: 136-141.

16. Ho Cho K, Kim HM, Kim Y, Yang S, Choi H (2018) Multiple inputs-single accumulated output mechanism for soft linear actuators. Journal of Mechanisms and Robotics 11: 011007.

17. Han MW, Ahn SH (2017) Blooming knit flowers: Loop-linked soft morphing structures for soft robotics. Adv Mater 29: 1606580.

18. Lancia F, Ryabchun A, Nguindjel AD, Kwangmettatam S, Katsonis N (2019) Mechanical adaptability of artificial muscles from nanoscale molecular action. Nature Communications 10: 4819.

19. Misaki Y, Naoki O, Minoru H, Midori T, Toshihiro H, et al. (2009) A contraction type soft actuator using poly vinyl chloride gel. IEEE International Conference on Robotics and Biomimetics, 22-25.

20. Ganguly S, Maity PM, Subhadip M, Poushali D, Poushali B, et al. (2018) Polysaccharide and poly (methacrylic acid) based biodegradable elastomeric biocompatible semi-IPN hydrogel for controlled drug delivery. Materials Science and Engineering: C 92: 34-51.

21.Amiri M, Khazaeli $P$, Salehabadi $A$, Salavati-Niasarie $M$ (2020) Hydrogel beads-based nanocomposites in novel drug delivery platforms: Recent trends and developments. Advances in Colloid and Interface Science, 102316.

22.Ganguly S, Das P, Das NC (2020) Characterization tools and techniques of hydrogels. Hydrogels Based on Natural Polymers 481-517. 
23.Ganguly S, Das P, Banerjee S, Das NC (2019) Advancement in science and technology of carbon dot-polymer hybrid composites: A review. Functional Composites and Structures 1: 022001.

24.Alavi F, Emam Djomeha Z, Salami M, Mohammadian M (2020) Effect of microbial transglutaminase on the mechanical properties and microstructure of acid-induced gels and emulsion gels produced from thermal denatured egg white proteins. International Journal of Biological Macromolecules 153: 523-532.

25.Amiri M, Salavati-Niasari M, Akbari A (2019) Magnetic nanocarriers: Evolution of spinel ferrites for medical applications. Advances in Colloid and Interface Science 265: 29-44.

26.Masjedi-Arani M, Salavati-Niasari M (2016) A simple sonochemical approach for synthesis and characterization of $\mathrm{Zn} 2 \mathrm{SiO} 4$ nanostructures. Ultrasonics Sonochemistry 29: 226-235.

27.Salahuddin BB (2020) Hydrogel based braided artificial muscles. Doctor of Philosophy from the University of Wollongong Australia.

28. Mirvakili MS (2017) High performance materials for artificial muscles and energy storage devices. Department of Mechanical Engineering, Massachusetts Institute of Technology, USA.

29.Li S, Vogt DM, Rus D, Wood RJ (2017) Fluid-driven origami-inspired artificial muscles. PNAS 114: 1313213137.

30.Šitum Z, Trslić P (2018) Ball and beam balancing mechanism actuated with pneumatic artificial muscles. J Mechanisms Robotics 10: 055001.

31. Mitsui T, Ohshima H (2012) Theory of muscle contraction mechanism with cooperative interaction among cross bridges. Biophysics 8: 27-39.

32.Krans JL (2010) The sliding filament theory of muscle contraction. Nature Education 3: 66.

33. Mitsui T, Ohshima H (2016) Modeling muscle contraction mechanism in accordance with sliding-filament theory. Encyclopedia of Biocolloid and Biointerface Science 2: 753-770.

34. Miriyev A, Stack K, Lipson H (2017) Soft material for soft actuators. Nature Communications 8: 596.

35.Jiao Z, Zhang C, Wang W, Huayong MP, Zou Y (2019) Advanced artificial muscle for flexible material-based reconfigurable soft robots. Adv Sci 6: 1901371.

36.Schaffner $M$, Jakob AF, Lucas $P$, Patrick AR, Fergal C, et al. (2018) 3D printing of robotic soft actuators with programmable bioinspired architectures. Nature Communications 9: 878.
37. Rudder BA (2017) Motor protein inspired, artificial muscle actuator. Engineering Faculty of Queensland University of Technology, Austraila.

38. Carlson GL (1990) A new approach to the baking soda-vinegar reaction. Chem Educ 67: 7-597.

39. Moeendarbary E, Ng TY, Zangeneh M (2010) Dissipative particle dynamics in soft matter and polymeric applications a review. International Journal of Applied Mechanics 2: 161-190.

40. Hoogerbrugge PJ, Koelman JMVA (1992) Simulating microscopic hydrodynamic phenomena with dissipative particle dynamics. EPL (Europhysics Letters) 19: 155.

41.Jafari S, Zakeri R, Darbandi M (2018) DPD simulation of non-Newtonian electroosmotic fluid flow in nanochannel. Molecular Simulation 44: 1444-1453.

42.Zakeri R (2019) Dissipative particle dynamics simulation of the soft micro actuator using polymer chain displacement in electro-osmotic flow. Molecular Simulation 45: 1488-1497.

43.Zakeri R, Sabouri M, Maleki A, Abdelmalek Z (2020) Investigation of magneto hydro-dynamics effects on a polymer chain transfer in micro-channel using dissipative particle dynamics method. Symmetry 12: 1-15.

44. Baker JS, McCormick M, Robergs RA (2010) Interaction among skeletal muscle metabolic energy systems during intense exercise. Nutrition and Metabolism.

45.Shim TS, Kim SH, Heo CJ, Jeon HC, Yang SM (2012) Controlled origami folding of hydrogel bilayers with sustained reversibility for robust microcarriers. Angew Chem 51: 1420-1423.

46. Yoshida R, Katsumi U, Yuzo K, Kiyotaka S, Akihiko K, et al. (1995) Comb-type grafted hydrogels with rapid deswelling response to temperature changes. Nature 374: 240-242.

47.Kim SJ, Han IK, Sang JP, Young KI, Sang HL, et al. (2005) Behavior in electric fields of smart hydrogels with potential application as bio-inspired actuators. Smart Mater Struct 14: 511-514.

48. Kondaveeti S, Semeano ATS, Cornejo DR, Ulrich H, Petri DFS (2018) Magnetic hydrogels for levodopa release and cell stimulation triggered by external magnetic field. Colloids Surf. B Biointerfaces 167: 415-424.

49.Potapov PL, Da Silva EP (2000) Time response of shape memory alloy actuators. Journal of Intelligent Material Systems and Structures 11: 125-134.

50.Acome E, Mitchel SK, Morrissey TG, Emmett MB, Benjamin C, et al. (2018) Hydraulically amplified self-healing electrostatic actuators with muscle-like performance. Science 359: 61-65. 